\title{
A dialética do ofuscamento
}

\author{
Elvis Cesar Bonassa*
}

Resumo: O texto procura mostrar que um dos elementos essenciais do conceito de "esclarecimento" empregado por Adorno e Horkheimer na Dialética do esclarecimento é o trabalho, forma de relação entre o homem e a natureza que se desenvolveu historicamente como um processo de dominação. Os autores teriam como pressuposto de sua análise a crítica marxista, mas acrescentando a ela uma dimensão kantiana: a questão da subjetividade. Mais especificamente, de acordo com o artigo a seguir, o fim da subjetividade, substituída pelo controle ou pelo autoritarismo, que mergulham a sociedade em um estado de ofuscamento. Nessa situação, qualquer teoria da revolução que tenha como pressuposto o surgimento de um sujeito revolucionário está de antemão condenada.

Palavras-chave: esclarecimento - trabalho - Escola de Frankfurt - marxismo - Kant - revolução - subjetividade

Para K.

O projeto da Dialética do esclarecimento, enunciado pelos autores no "Prefácio" escrito em 1947, articula-se em torno de duas teses centrais: "o mito já é esclarecimento e o esclarecimento acaba por reverter à mitologia". Assim expresso, o núcleo do texto remete, em primeiro lugar, a uma crítica da racionalidade e da civilização. É por exemplo a leitura de Habermas, que procura compreender o livro como uma tentativa - fracassada - de crítica da civilização em termos semelhantes à que fez Nietzsche a respeito do niilismo (Habermas 8, p. 140). Uma aproximação tradicional entre os comentadores da obra, que abre campo para uma série de análises culturais, psicológicas, históricas, formais. Uma tal leitura da Dialética do esclarecimento permitiria ver ali a repetição da denúncia nietzschiana de que, por trás das pretensões éticas e cognitivas, a racionalidade se revela como autoconservação e dominação.

\footnotetext{
* Mestrando do Departamento de Filosofia - FFLCH-USP e bolsista CAPES.
} 
Essa análise é redutora; pode levar ao equívoco de supor um objeto fixado a-historicamente, uma "racionalidade" que se limita a desenvolver, no transcurso de um tempo linear, os germes da autoconservação e dominação inscritos desde sempre em sua "essência". Mas não se trata, como tal interpretação levaria a supor e como já no título o próprio livro distingue, de uma dialética da "razão", e sim do "esclarecimento". Esses conceitos não são equivalentes. O capítulo inicial, "O conceito de esclarecimento", desfaz essa confusão. O esclarecimento é um processo histórico definido pela busca de "livrar os homens do medo e torná-los senhores".

Ao se perguntar o que causa medo e sobre o que os homens devem estabelecer seu senhorio, o caráter desse processo fica mais claro: trata-se da natureza. "O entendimento que vence a superstição deve imperar sobre a natureza desencantada" (Adorno e Horkheimer 2, p. 20). Desse modo, o esclarecimento é, antes de mais nada, no contexto da Dialética do esclarecimento, uma forma de relação entre homem e natureza. A interpretação começa a expandir suas fronteiras ao se perceber, então, que essa relação se dá como trabalho, voltado para o domínio da natureza. No processo de esclarecimento, dizem os autores, "a natureza não deve mais ser influenciada pela assimilação, mas dominada pelo trabalho" (idem, p. 32).

Adorno e Horkheimer estão longe de ignorar o caráter histórico do trabalho. As análises marxistas são, a esse respeito, num primeiro movimento conceitual, o pressuposto do livro. E é dentro dessa historicidade que a razão é analisada: ela desempenha seu papel como ferramenta inscrita no esclarecimento. É na história do trabalho que a racionalidade vai tendo seus traços definidos. O movimento, além de histórico, não se dá desligado das determinações econômicas. A máxima capacidade de domínio da natureza, o cume do esclarecimento e da razão matematizada e calculadora que lhe corresponde, é o capitalismo industrial. "A técnica é a essência desse saber, que não visa conceitos e imagens, nem o prazer do discernimento, mas o método, a utilização do trabalho dos outros, o capital" (idem, p. 20).

O papel determinante do trabalho, é bom notar, permanecerá constante nas análises frankfurtianas. Já em 1937, em "Filosofia e teoria crítica", Horkheimer afirmava: "Esse pensamento que considera como espiritual a atividade materialmente dada, situando-a na consciência supra-empírica em si, no Eu absoluto, no Espírito, é geral no idealismo alemão. (...) Para a concepção materialista, ao 
contrário, essa atividade fundamental consiste no trabalho social, cujo caráter de classe imprime sua forma em todos os modos do reagir humano, inclusive na teoria" (Horkheimer 9, p. 156, grifo nosso). Mais de 20 anos depois, Adorno retoma o mesmo argumento em "Aspectos", texto dedicado a Hegel: “o mundo, enquanto forme um sistema, o fará justamente por meio da cerrada universalidade do trabalho social, o qual é, de fato, a mediação radical; e, do mesmo modo que o era entre o homem e a natureza, o será dentro do espírito para si, que não tolera nada fora" (Adorno 1, p. 44, grifo nosso) ${ }^{1}$.

A Dialética do esclarecimento, situada cronologicamente entre esses dois textos, move-se no mesmo terreno. O trabalho como dominação da natureza gera uma racionalidade também voltada para a dominação. Com respeito a Marx, o movimento é pelo menos duplo. Em primeiro lugar, aceita-se a análise marxista do trabalho como forma de relação homem/natureza, de dominação da natureza, e suas conseqüências para a organização da sociedade. O segundo passo é crítico: o processo de dominação da natureza desenvolveu-se também como dominação do homem (até aqui ainda não seria preciso separar-se de Marx), mas de tal forma que em seu ponto de máximo de desenvolvimento - a sociedade industrial - desaparece a possibilidade da construção de uma sociedade emancipada.

A técnica acoplada ao trabalho atingiu um tal poder que englobou também os homens sob a forma de natureza, ou seja, como objetos, como seres destituídos de subjetividade. Esse é um dos sentidos do conceito de "mito" empregado na Dialética do esclarecimento: se desde o início o trabalho separou progressivamente homens e natureza, no seu máximo desenvolvimento ele os reuniu novamente. Em vez da "humanização da natureza", ocorre a "naturalização da humanidade", formando uma totalidade à disposição do único sujeito, o capital. "A naturalização dos homens hoje em dia não é dissociável do progresso social. O aumento da produtividade que por um lado produz as condições para um mundo mais justo, confere por outro lado ao aparelho técnico e aos grupos sociais que os controlam uma superioridade imensa sobre o resto da população. $\mathrm{O}$ indivíduo se vê completamente anulado em face dos poderes econômicos. Ao mesmo tempo, estes elevam o poder da sociedade sobre a natureza a um nível jamais visto" (Adorno e Horkheimer 2, p. 14).

O que Adorno e Horkheimer desenham é um cenário do eterno retorno da dominação. A passagem para uma sociedade com a produção planificada, 
racionalmente gerida, que em Marx aparecia como sinônimo de uma sociedade liberada ${ }^{2}$, pode se dar também como perpetuação da não-liberdade. Efetivamente, a emancipação, de acordo com o próprio marxismo, depende de um sujeito revolucionário. Marx o via surgir no proletariado. As idéias posteriores de vanguarda e de consciência de classe procuraram dar solução ao fato de que, ao invés de buscar uma sociedade mais livre, o proletariado oscilava entre a apatia e o fascismo. É neste ponto que a análise de Adorno e Horkheimer toca a questão da racionalidade, dentro do processo do esclarecimento. Para eles, não é possível surgir um tal sujeito revolucionário liberador porque a sociedade industrial desenvolveu mecanismos reais de pre-formação dos indivíduos e das consciências que excluem a priori a possibilidade da liberdade.

Há aqui um forte pressuposto kantiano, que Adorno não cessará de tematizar em toda a sua obra: é impossível supor uma sociedade livre, uma verdadeira humanidade, sem que os indivíduos se tornem capazes de uma subjetividade autônoma ${ }^{3}$. Esse é o sentido de algumas das principais críticas levantadas por Adorno contra os partidos comunistas e as organizações coletivistas - e está também no centro de suas diferenças em relação a Brecht. A coletividade de proletários acabaria por se reverter no mesmo conjunto totalitário do qual pretendia se libertar ${ }^{4}$. Mesmo uma sociedade pós-capitalista que empregue os mesmos padrões da racionalidade técnica engendrada no processo de dominação da natureza e faça do trabalho e do desenvolvimento das forças produtivas seu eixo, ela será uma sociedade não-emancipada. É necessário insistir em que Adorno não considera a racionalidade desvinculada dos processos produtivos. O último aforisma da segunda parte das Minima moralia, escrito em 1945, toca exatamente nesse ponto: "Uma sociedade liberada das cadeias que a acorrentam poderia bem tomar consciência de que as forças produtivas não são o substrato último do homem, mas representam tão somente a forma histórica do homem adequada à produção de mercadorias". A possibilidade de "rien faire comme une bête", afirma Adorno em francês, é uma das características da sociedade emancipada (Adorno 3, p. 138) . 


\section{Um Marx kantiano: crítica e metacrítica}

Estamos diante de uma espécie de "fim da história": a sociedade industrial gera seres humanos incapazes de se organizar de outra maneira a não ser reproduzindo os mecanismos de dominação dessa mesma sociedade ${ }^{6}$. Numa démarche marxista-kantiana, a argumentação da Dialética do esclarecimento vai operar com a contraposição dos conceitos de autonomia do sujeito e alienação. O objetivo é mostrar que, levada a seu ponto máximo, a alienação aniquilou a subjetividade e, com ela, a possibilidade de ações liberadoras. "O trabalho social de todo indivíduo está mediatizado pelo princípio do eu na economia burguesa; a um ele deve restituir o capital aumentado, a outro a força para um excedente de trabalho. Mas quanto mais o processo de autoconservação é assegurado pela divisão burguesa do trabalho, tanto mais ele força a autoalienação dos indivíduos, que têm de se formar no corpo e na alma segundo a aparelhagem técnica. (...) A subjetividade volatizou-se na lógica das regras do jogo pretensamente indeterminadas" (Adorno e Horkheimer 2, p. 41).

Ao analisar a Crítica da razão pura, os autores insistem em que a possibilidade de uma sociedade emancipada depende de uma subjetividade livre: "A razão contém, enquanto ego transcendental supra-individual, a Idéia de uma convivência baseada na liberdade, na qual os homens se organizem como um sujeito universal e superem o conflito entre a razão pura e a empírica na solidariedade consciente do todo. A Idéia desse convívio representa a verdadeira universalidade, a Utopia “ (idem, p. 83). Mas ocorre que essa dimensão universalizadora foi dissolvida em favor de uma totalidade não consciente, controlada. A formulação se completa, em termos kantianos, delimitando o círculo mágico (Bannkreis) desenhado pela Dialética do esclarecimento: a passagem para uma sociedade justa depende da subjetividade, mas esta foi aniquilada. "Aparentemente o próprio sujeito transcendental do conhecimento acaba por ser suprimido como a última reminiscência da subjetividade e é substituído pelo trabalho tanto mais suave dos mecanismos automáticos de controle. (...) $\mathrm{O}$ processo técnico, no qual o sujeito se coisificou após sua eliminação da consciência, está livre da plurivocidade mítica bem como de toda a significação em geral, porque a própria razão se tornou um mero adminículo da aparelhagem econômica que a tudo engloba" (idem, pp. 41-42).

O uso do conceito de alienação na Dialética do esclarecimento se aproxima muito dos Manuscritos econômico-filosóficos de Marx ${ }^{7}$. A armação 
conceitual dos Manuscritos favorece a aproximação com Kant. Ali, Marx expõe a alienação em quatro níveis: em relação ao produto do trabalho, em relação ao próprio processo de trabalho e, como conseqüência, em relação ao ser genérico do homem (Gattungswesen), e finalmente de cada homem em relação aos outros homens. Tal "ser genérico", conceito hegeliano filtrado por Feuerbach, ganha uma definição que engloba elementos de universalidade e liberdade que caracterizam o sujeito da razão prática kantiana: "O homem é um ser genérico, não só no sentido de que faz objeto seu, prática e teoricamente, a espécie (tanto a sua própria como a das outras coisas), mas também - e agora trata-se apenas de uma outra expressão para a mesma coisa - no sentido de que ele se comporta perante si próprio como perante a espécie viva, como ser universal, e portanto livre" (Marx 13, p. 163, grifo nosso). A alienação tira dos homens a universalidade e a liberdade, rouba-lhes a condição de sujeitos. Pelos mecanismos da alienação, a atividade humana se converte em mero interesse individual pela autoconservação, "como o único meio da satisfação de uma necessidade, a de manter a existência física" (idem, p. 164).

Ora, boa parte do argumento de Adorno e Horkheimer já está exposta nessa passagem de Marx: a sociedade burguesa substitui a autonomia pela autoconservação. Os homens se vêem contrapostos a uma totalidade que lhes aparece como estranha e que os controla. Adorno e Horkheimer se referem mesmo ao conceito de "ser genérico" na Dialética do esclarecimento, ironicamente: "A indústria cultural realizou maldosamente o homem como ser genérico. Cada um é somente aquilo mediante o que pode substituir todos os outros: ele é fungível, ele é mero exemplar" (Adorno e Horkheimer 2, p. 136). Mas, enquanto em Marx essa situação lança os indivíduos em um "esvaziamento" da subjetividade que será superado revolucionariamente, para Adorno e Horkheimer há um elemento a mais: uma falsa subjetividade, constituída pelo mecanismos de controle, substitui a subjetividade evaporada e funciona como bloqueio. Por meio de seu princípio de individuação homogeneizadora, a sociedade produz subjetividades falsas (porque privadas de liberdade e espontaneidade) que realizam a universalidade da total adaptação, mediada pelo trabalho social alienado - "a mediação radical".

Um dos aforismas das Minima moralia inclui mesmo na teoria marxista da revolução um certo grau de arbitrariedade, ao atribuí-la à "intenção" que a movimenta: "A verdade ou inverdade da dialética não está no método enquanto 
tal, mas em sua intenção no processo histórico. (...) Não é dialética a doutrina de Marx apenas, segundo a qual o proletariado enquanto objeto absoluto da história seria capaz de se tornar seu primeiro sujeito social, de realizar a autodeterminação consciente da humanidade, mas também a anedota que Gustave Doré atribui a um representante parlamentar do Ancien Régime: que, sem Luís XVI, jamais teria havido revolução e que, por isso, a ele se deveriam os direitos humanos" (Adorno 3, p. 214).

As considerações feitas até aqui podem servir para mostrar que, se há igualmente continuidades e rupturas entre a Dialética do esclarecimento e o marxismo, essas rupturas se dão como radicalização da crítica em um eixo central da reflexão de Marx. Embora a influência de Max Weber também pareça determinante, em grande parte devido ao conceito de desencantamento do mundo, há diferenças metodológicas marcantes em relação a esse autor. Em A metodologia das ciências sociais, Weber combate o método marxista de análise, baseado na relação de determinação entre infra-estrutura econômica e superestrutura política e cultural. Para Weber, a tarefa do conhecimento histórico ou sociológico pressupõe a eleição de pontos de vista, premissas "subjetivas", que se debruçam sobre elementos da realidade "que apresentam alguma relação, por muito indireta que seja, com o acontecimento a que conferimos uma significação cultural" (Weber 16, pp. 131-132). Na Dialética do esclarecimento, o abandono da análise econômica propriamente dita, a escolha de temas que pertencem igualmente à literatura e à história, o estudo empírico de casos psicológicos poderiam sugerir que se trata de procedimentos que optam pela escolha dos pontos de vista que pareceram, ao pesquisador, mais adequados a seu objeto.

Essa seria, no entanto, uma conclusão sujeita a críticas. Adorno e Horkheimer focalizam, numa análise materialista, um ponto cego do marxismo: a teoria da revolução, que pressupõe a possibilidade da formação de uma subjetividade revolucionária, criando uma alternativa para a barbárie dentro do campo do desenvolvimento das forças de produção capitalista. A Dialética do esclarecimento procura explorar exatamente as razões pelas quais essa teoria falhou: o desenvolvimento das forças produtivas, em vez de lançar as bases de uma sociedade justa, tanto sustenta o totalitarismo como perpetua a injustiça sob a forma democrática. Ou seja, a análise não elege um ponto de vista entre outros, mas se debruça propriamente sobre o ponto em que a obra de Marx perde a 
eficácia teórica. É, nesse sentido, uma metacrítica da economia política.

\section{Relações obscuras}

Ao inserir a questão da subjetividade na formulação marxista, a Dialética do esclarecimento abre campo para a análise dos mecanismos concretos de individuação na sociedade capitalista. É na constituição dessa falsa subjetividade, por exemplo, que a indústria cultural encontra seu lugar, como alternativa equivalente, nesse sentido, ao totalitarismo que opera a homogeneização social pela violência. Se Adorno tinha como exemplos imediatos de totalitarismo a sociedade soviética e o nazismo, ele estava igualmente convivendo com a sociedade de consumo nos Estados Unidos, onde se exilou a partir de 1938. A ampliação da esfera de consumo (aí incluída a indústria cultural) e sua função na sociedade norte-americana forneceram a Adorno elementos decisivos para a elaboração do conceito de falsa subjetividade. Veja-se, por exemplo, a "Dedicatória" das Minima moralia, que põe em jogo alguns dos conceitos centrais da Dialética do esclarecimento: "Aquilo que 'vida' significava outrora para os filósofos passou a fazer parte da esfera privada e, mais tarde ainda, da esfera do mero consumo, que o processo de produção material arrasta consigo como um apêndice sem autonomia e sem substância própria" (Adorno 3, p. 7).

Mais do que um mecanismo de controle a posteriori, a indústria cultural constitui o a priori da falsa subjetividade destinada aos indivíduos. Tornado sujeito, o capital monopoliza a consciência. "A função que o esquematismo kantiano ainda atribuía ao sujeito", dizem Adorno e Horkheimer no capítulo dedicado à indústria cultural, "a saber, referir de antemão a multiplicidade sensível aos conceitos fundamentais, é tomada pela indústria. O esquematismo é o primeiro serviço prestado por ela ao cliente. (...) Ao subordinar da mesma maneira todos os setores da produção espiritual a este fim único: ocupar os sentidos dos homens da saída da fábrica, à noitinha, até a chegada ao relógio de ponto, na manhã seguinte, com o selo da tarefa de que devem se ocupar durante o dia, essa subsunção realiza ironicamente o conceito da cultura unitária que os filósofos da personalidade opunham à massificação" (Adorno e Horkheimer 2, pp. 117 e 123).

A argumentação está radicada no cruzamento entre os conceitos de 
indivíduo, sujeito e sociedade. Adorno joga com ambigüidades, tendo como horizonte a impossibilidade da passagem, em Kant, do sujeito transcendental ao caráter inteligível. Essa impossibilidade (que receberá tratamento extenso na Dialética negativa - cf. Adorno 4, pp. 283-292), é referida na Dialética do esclarecimento: "As dificuldades do conceito de razão, provenientes do fato de que seus sujeitos, os portadores de uma e mesma razão, se encontrem em oposição uns aos outros, estão escondidas no esclarecimento ocidental por trás da aparente clareza de seus juízos. Na Crítica da razão pura, ao contrário, elas se exprimem na relação obscura do ego transcendental com o ego empírico e nas demais contradições não resolvidas" (idem, p. 83) ${ }^{8}$.

Essas dificuldades conceituais e relações obscuras são, para Adorno e Horkheimer, a expressão de uma situação social de fato. Se Kant, em seu rigorismo crítico, acaba por se ver obrigado a "um golpe de força" para tentar vencer a impossibilidade de fundamentação racional da moral, é porque esse domínio, na prática, já está vencido. "Sua tentativa de derivar de uma lei da razão o dever do respeito mútuo - ainda que empreendida de maneira mais prudente do que toda a filosofia ocidental - não encontra nenhum apoio na crítica. É a tentativa usual do pensamento burguês de dar à consideração, sem a qual a civilização não pode existir, uma fundamentação diversa do interesse material e da força, sublime e paradoxal como nenhuma outra tentativa anterior, e efêmera como todas elas" (idem, p. 85). A análise da obra do Marquês de Sade, no "Excurso II", procura demonstrar a indiferença e frieza da racionalidade frente aos homens. Levado ao limite, o "entendimento sem a direção de outrem" converte-se na pura violência. "Ao contrário de seus apologetas, os escritores sombrios da burguesia não tentaram distorcer as conseqüências do esclarecimento recorrendo a doutrinas harmonizadoras. Não pretenderam que a razão formalista tivesse uma ligação mais íntima com a moral do que com a imoralidade" (idem, p. 111).

A subjetividade de empréstimo, ao lado da racionalidade técnica, se exprime na sociedade e nos indivíduos como barbárie. O anti-semitismo, analisado no capítulo final da Dialética do esclarecimento, ganha o status de paradigma. "O comportamento anti-semita é desencadeado em situações em que os indivíduos obcecados e privados de sua subjetividade se vêem soltos como se fossem sujeitos" (idem, p. 160, grifo nosso). É um ativismo cego, privado de experiência, uma regressão ao estado selvagem. Sem capacidade 
de reflexão, os indivíduos simulam a subjetividade afirmando a liberdade puramente física da violência ${ }^{9}$. O anti-semitismo é o limite da progressão do esclarecimento: "Não lhe foi concedendo a plena satisfação que os colossos desencadeados na produção superaram o indivíduo, mas extinguindo-o como sujeito. É nisso justamente que consiste sua racionalidade consumada, que coincide com sua loucura" (idem, p. 191). É um contexto geral de ofuscamento (Verblendungszusammenhang), no qual as pessoas deixam de ouvir a "voz da consciência" e passam a "ouvir vozes".

Em busca do sujeito, a análise se desenvolve numa contínua troca de planos. Do mais abstrato sujeito transcendental kantiano, passando por sua "concretização" na indústria cultural, atinge a psicologia ${ }^{10}$. Em vez da interiorização de normas morais - já que, a rigor, não há mais interioridade subjetiva -, os indivíduos adotam uma "identificação pronta e imediata com escalas de valores estereotipadas". É o pensamento por tickets. Essa conceituação foi desenvolvida por Adorno poucos anos antes da elaboração da Dialética do esclarecimento para servir de metodologia a uma pesquisa empírica sobre a personalidade autoritária. O ticket é um conjunto de pontos ideológicos organizados em bloco. Ao dizer "sim" a qualquer um dos pontos desse ticket, o indivíduo adere imediatamente, sem reflexão, a todos os outros. "Quem dá uma chance qualquer ao fascismo subscreve automaticamente, juntamente com a destruição dos sindicatos e a cruzada anti-bolchevista, a eliminação dos judeus" (idem, p. 187). O indivíduo dotado da falsa subjetividade é incapaz de juízo: ele precisa se orientar de acordo com alguma direção dominante.

Esse acolhimento irrefletido de um pacote de valores faz com que seja de menor importância se o seu conteúdo é progressista ou fascista. O problema, apontam Adorno e Horkheimer, é que a mentalidade do ticket, por si só, está ligada à intolerância: "Não é só o ticket anti-semita que é anti-semita, mas a mentalidade do ticket em geral". De tal forma que não se trata de uma verdadeira escolha, mas imperativo da sobrevivência, guiada por critério semelhantes aos da escolha de um produto para consumo. "A escolha do ticket comunista ou do ticket fascista depende da impressão que o Exército Vermelho ou os laboratórios do Ocidente deixam no indivíduo. A reificação, graças à qual a estrutura de poder, possibilitada apenas pela passividade das massas, aparece às próprias massas como uma realidade indestrutível, tornou-se tão densa que toda espontaneidade e mesmo a simples idéia da verdadeira situação tornou-se 
necessariamente uma utopia extravagante, um desvio sectarista. Escolher um ticket significa adaptar-se a uma aparência petrificada como realidade e que se prolonga a perder de vista graças a essa adaptação" (idem, p. 191). É preciso observar que a conexão da mentalidade do ticket com o trabalho é afirmada explicitamente: "A base da evolução que conduz à mentalidade do ticket é, de qualquer modo, a redução universal de toda energia específica a uma única forma de trabalho, igual e abstrata, do campo de batalha ao estúdio cinematográfico" (idem, p. 193)

Se o processo de perda da subjetividade engolfou a sociedade e chegou ao ponto de atingir as estruturas psíquicas - "os sujeitos da economia pulsional são expropriados psicologicamente e essa economia é gerida mais racionalmente pela própria sociedade" -, onde encontrar os elementos emancipadores relacionados à autonomia do sujeito, considerados indispensáveis? A Dialética do esclarecimento traçou um círculo de ferro para o qual não há saída. Trabalho social alienado, dominação, dissolvimento da subjetividade e racionalidade técnica engendram uma totalidade que se repõe continuamente, em estremecimentos que antes expressam os movimentos assustadiços da paranóia institucionalizada do que qualquer possibilidade de passagem a uma sociedade justa. Ofuscada, a sociedade mantém sua organização desumana e injusta - para usar uma expressão de José Arthur Giannotti, em estado de fibrilação ${ }^{11}$.

\begin{abstract}
The present article tries to show that one of the key elements of the concept of enlightenment used by Adorno and Horkheimer in their Dialetics of enlightenment is work, e.g., a form of relation between man and nature that has developed along history as a domination process. Their analysis had presupposed the marxist critic but adding a kantian element to it: the question of subjectivity. More especifically, the end of subjectivity, replaced by control or by authoritarism - both bringing society into a state of blindness. Consequently, any theory of revolution that has, as its assumption, the arise of a revolutionary subject is condemned beforehand.
\end{abstract}


Key-words: enlightenment - work - Frankfurt School - marxism - Kant - revolution subjectivity

\section{Notas}

1. O conceito de trabalho social aqui empregado, com sua capacidade universalizadora, vem do marxismo. Adorno mostra, em "Aspectos", de que modo a totalidade hegeliana, "princípio do ser e do pensar", se revelava, na obra de Marx, como trabalho social. Comentando um trecho dos Manuscritos econômico-filosóficos, ele afirma: "O momento de universalidade do ativo sujeito transcendental frente ao meramente empírico, isolado e contingente, não é uma simples quimera, como tampouco o é a validade das proposições lógicas frente aos atos mentais individuais singulares; pelo contrário, tal universalidade é a expressão exata, ao mesmo tempo - tendo em conta a tese geral idealista - oculta aos seus olhos, da essência social do trabalho" (Adorno 1, p. 35). O texto de Marx a que Adorno se refere é o seguinte: "A grandeza da fenomenologia hegeliana e seu resultado, a dialética, a negatividade como motor e engendrador, consiste (...) em que capta a essência do trabalho e concebe os homens objetivos, verdadeiros por serem homens reais, como resultado de seu próprio trabalho", de acordo com a citação de Adorno (Adorno 1, p. 35; cf. Marx 13, p. 245).

2. Por exemplo, em A ideologia alemã, um “controle e domínio consciente desses poderes que, engendrados pela ação recíproca dos homens, impuseram-se a eles como poderes totalmente estranhos e que os dominaram" (Marx 12, p. 54, grifo nosso),

3. Cf., por exemplo, "Educação pós-Auschwitz": "A única força verdadeira contra o princípio de Auschwitz seria a autonomia, se me for permitido empregar a expressão kantiana." (Adorno 5, p. 110)

4. Em carta a Walter Benjamin, em 2 de agosto de 1935, Adorno afirma que o "coletivo" é uma das razões de sua reserva em relação a Brecht. "Esta tem sido minha atual reserva sobre Berta [pseudônimo de Brecht na correspondência entre ambos]. Seu 'coletivo' e seu não-mediado conceito de função são suspeitos para mim, como 'regressão"' (Benjamin 6, p. 498).

5. Para uma análise da necessidade de crítica ao conceito de trabalho em Marx, a partir de Horkheimer, cf. o artigo de Moishe Postone e Barbara Brick, "Critical Theory and Political Economy" (Postone e Brick 15, pp. 215-250). Nesse artigo, os autores discutem ainda a influência de Pollock sobre as formulações de Horkheimer.

6. Do ponto de vista da economia política, Adorno e Horkheimer podem encontrar susten- 
tação nas análises de Friedrich Pollock, a quem a Dialética do esclarecimento é dedicada. Para Pollock, o capitalismo atingira uma fase em que o processo econômico passa a sofrer controle direto das burocracias estatais, possibilitando considerar o primado da política sobre a economia sob condições não-socialistas. A esse respeito, cf. A ontologia do estado falso (Nobre 14, capítulo 1) e "Critical Theory and Political Economy" (Postone e Brick 15 , pp. 215-250).

7. O Instituto para a Pesquisa Social recebeu uma cópia dos Manuscritos econômicofilosóficos já na década de 20, por meio de David Ryazanov, diretor do Instituto MarxEngels, de Moscou. Ryazanov esteve posteriormente em Frankfurt e publicou um artigo na revista do Instituto, em 1930 (cf. Jay 11, pp. 13-19)

8. Confira-se ainda, a esse respeito, "Sobre sujeito e objeto": "Em se tratando de considerações sobre sujeito e objeto, a dificuldade consiste em indicar do que se deve propriamente falar. É notório que os termos são equívocos. Assim, sujeito pode referir-se tanto a indivíduo particular quanto a determinações gerais; de acordo com os termos dos Prolegômenos kantianos, à consciência em geral. A ambigüidade não pode ser eliminada simplesmente mediante um classificação terminológica. Pois ambas as significações necessitam-se mutuamente; mal podemos apreender uma sem a outra" (Adorno 5, p. 181)

9. Essa liberdade puramente física, sem conteúdo moral, está ligada ao totalitarismo pelo menos desde Hobbes: "Liberdade significa, em sentido próprio, a ausência de oposição (entendendo por oposição os impedimentos externos do movimento); e não se aplica menos às criaturas irracionais e inanimadas do que às racionais. (...) Mas sempre que as palavras 'livre' e 'liberdade' são aplicadas a qualquer coisa que não seja um corpo, há um abuso de linguagem; porque o que não se encontra sujeito ao movimento não se encontra sujeito ao impedimento" (Hobbes 10, p. 130).

10. O apelo à psicologia e à psicanálise não pretende ser o fundamento da explicação, mas um de seus momentos, como afirma Adorno em "Experiências científicas nos Estados Unidos": "Os elementos do anti-semitismo enquadraram teoricamente o preconceito racial no contexto de uma teoria crítica da sociedade objetivamente orientada. Por certo, ao contrário de certa ortodoxia economicista, não nos tornamos ariscos em relação à psicologia, mas sim lhe outorgamos em nosso projeto o valor que lhe correspondia como momento da explicação. Mas nunca duvidamos da primazia dos fatores objetivos sobre os psicológicos" (Adorno 5, p. 160).

11. Em Certa herança marxista, livro em preparação que serviu de base a um curso de pós-graduação do Departamento de Filosofia da USP (primeiro semestre de 1997), ao fazer a leitura dos Grundrisse de Marx, José Arthur Giannotti se aproxima das reflexões dos frankfurtianos. Acompanhemos o texto (as citações seguintes foram extraídas de Giannotti 7, cap. III, pp. 58-69). Marx afirma que o desenvolvimento tecnológico provoca uma alteração fundamental na estrutura do capitalismo. (1) A relação do homem com o trabalho se altera, na medida em que ele se comporta "muito mais como o vigilante e regulador do processo de produção (...). Ele comparece ao lado do processo de produção em vez de ser 
seu agente principal". (2) O tempo de trabalho deixa de ser medida da riqueza, já que a tecnologia absorve, na forma de ciência e dominação da natureza, a força produtiva geral, fazendo com que "o roubo do trabalho alheio, sobre o qual hoje se assenta a riqueza, pareça um fundamento miserável, se comparado com a nova riqueza gerada pela nova indústria recentemente desenvolvida". (3) A explosiva produtividade tecnológica torna a criação da riqueza independente do tempo de trabalho empregado para sua produção, gerando tempo livre para os homens. Isso coloca em xeque o próprio fundamento da riqueza capitalista, a apropriação do sobretrabalho alheio, que deixa de ser relevante. Para se manter enquanto sistema, o capitalismo enfrenta a contradição de tornar supérfluo o trabalho humano, mas continuar dependendo dele como medida da riqueza. Se, como observa Giannotti, essa contradição tende a levar ao "colapso formal do capitalismo, à indeterminação de suas categorias e a diminuição de seu caráter social, não é por isso que coloca qualquer obstáculo ao desenvolvimento das forças produtivas". Marx acreditava, sublinha Giannotti, que o tempo tornado disponível faria surgir um indivíduo social como força produtiva em oposição às formas de relação social do capitalismo. Pela via da sujeito, havia a esperança da passagem ao socialismo. Ora, observa Giannotti, isso não leva em conta "uma dificuldade que Marx não podia perceber, porquanto esse fenômeno só se desenvolve muitos anos depois (...): que este indivíduo social seria ele mesmo apropriado pelo capital pelas garras do consumo". Assim capturado, perderia a capacidade de se firmar efetivamente como sujeito, permanecendo como "uma massa de consumidores vorazes [contexto no qual o conceito de Verblendungszusammenhang talvez pudesse ser traduzido por "deslumbramento geral", ECB], que tudo fazem menos se conformar a uma individualidade social", ao lado da grande massa de "miseráveis periféricos".

\section{Referências Bibliográficas}

1. ADORNO, Theodor W., “Aspectos”, trad. V. S. Zavala, em: Tres estudios sobre Hegel, Madri, Taurus, 1974.

2. ADORNO, Theodor W. e HORKHEIMER, Max, A dialética do esclarecimento, trad. G.A. Almeida, Rio de Janeiro, Jorge Zahar Editor, 1985.

3. ADORNO, Theodor W., Minima moralia, trad. L.E. Bicca, São Paulo, Ática, 1992. 
4. . Negative Dialektik, Frankfurt, Suhrkamp, 1980.

5. . Palavras e sinais, trad. M.H. Ruschel, Petrópolis, Vozes, 1995.

6. BENJAMIN, Walter, Correspondence, trad. M.R. Jacobson e E.M. Jacobson, Chicago, The University of Chicago Press, 1994.

7. GIANNOTTI, José Arthur, Certa herança marxista, mimeo, 1997.

8. HABERMAS, Jürgen, El discurso filosófico de la modernidad, trad. M.J. Redondo, Madri, Taurus, 1989.

9. HORKHEIMER, Max, "Filosofia e teoria crítica", trad. E.A. Malagodi e R.P. Cunha, em: Textos escolhidos, São Paulo, Abril, 1983 (col. Os pensadores).

10. HOBBES, Thomas, Leviatã , trad. J.P. Monteiro e M.B.N. Silva, São Paulo, Abril, 1983 (col. Os pensadores).

11. JAY, Martin, The Dialectical Imagination, Boston, Little Brown, 1973.

12. MARX, Karl e ENGELS, Friedrich, A ideologia alemã, trad. J.C. Bruni e M.A. Nogueira, São Paulo, Hucitec, 1984.

13. MARX, Karl, Manuscritos económicos-filosóficos, trad. A. Morão, Lisboa, Edições 70, 1993.

14. NOBRE, Marcos, A ontologia do estado falso, FFLCH-USP, mimeo, 1997.

15. POSTONE, Moishe e BRICK, Barbara, "Critical theory and political economy”, em: On Max Horkheimer, Massachusetts, The MIT Press, 1993.

16. WEBER, Max, A metodologia das ciências sociais, São Paulo, Cortez, 1993, vol. I. 